\title{
Teaching Method and Application of New Media Technology
}

\author{
Guoshao Chen \\ School of Computer Science and Engineering \\ Xi'an Technological University, Xi'an, 710021, China \\ e-mail: 1825247141@qq.com
}

\begin{abstract}
With the continuous and long development of human society, a great deal of media information has been produced, such as music, pictures and videos. Media information has made information exchange more and more popular. Its development includes traditional character information, TV video media and Internet media. This paper research on the technology and application of new media . First introduced the concept of media and new media. Followed by the introduction of new media information from production to dissemination of technology, including hardware, storage systems technology, compression technology and transmission technology. Finally, with the help of the mobile terminal, the user can complete applications such as mobile payment, mobile reading and online learning.
\end{abstract}

\section{Keyword-New Media; Storage; Compression; Transmission}

\section{MEDIA AND NEW MEDIA}

There are two kinds of media definitions, one is the method of information communication between man and the outside world, and the other is the carrier of information transmission. New media is a new media form developed by traditional media, such as newspapers, radio, television and so on. The new media can carry the information it carries in the most efficient way to spread it in order to maximize the value of the information.

New media can be divided into online media, television media and mobile media in terms of modes of communication. New media technology relies on traditional computer technology. First of all, because of the huge amount of information on new media, it is necessary to have the corresponding hardware facilities to process the

\author{
Lai Yufeng \\ School of Computer Science and Engineering \\ Xi'an Technological University, Xi'an, 710021, China \\ e-mail:604612675@qq.com
}

information. Second, the computer needs to have enough storage space to store large amounts of information. At the same time, an efficient transmission system is also necessary in order to ensure the timeliness of new media information. The emergence of new media technologies depends on hardware systems, storage systems and transmission systems. Therefore, computer technology and network development are the basic conditions for the birth of new media.

\section{NEW MEDIA MAIN TECHNOLOGY}

The general process of new media information processing is shown as bottom Fig1.

\section{A. Hardware system}

New media information needs to be preprocessed through the computer, which is a type of digital media. Media mainly includes sound, images and video, using hardware facilities for sound cards and video cards.

\section{1) Audio technology}

The audio master in the media message is processed by the sound card. Sound card is not only part of the multimedia computer, but also to achieve the conversion of $\mathrm{A} / \mathrm{D}$ (analog signals / digital signal)components. The performance of a sound card affects the audio effects in a multimedia system. Audio processing mainly includes compression and synthesis. Compression can be classified as lossy compression and lossless compression, depending on the sound quality and storage space requirements can choose different compression. Synthesis includes FM synthesis and wavetable synthesis. Audio usually choose different storage formats according to different compression codes, including WAV, WMA, MP3, MIDI and so on. 


\section{2) Image video technology}

Pictures and videos in media messages are mainly processed using graphics cards. As graphics technology continues to improve, the quality of graphics, graphics and video that computers can display is getting better.

\section{B. Storage system technology}

New media information is an electronic resource and needs enough space to store it. With the continuous accumulation of media information, its storage system requirements will be higher.

In a computer system, a memory that stores programs and data is a memory device, and the memory can be divided into an external memory and an internal memory. Computer storage technology is constantly evolving and updating. External memory not only increased storage capacity, but also increased access speed, the existence of the form from the tape into a SSD solid state drive. In general, having a large capacity and efficient storage system is an integral part of new media.

\section{Compression technology}

The media is digitized to produce a lot of data, the key technology to solve the problem of taking up a lot of storage space is the data compression technology. The essence of data compression is to reduce the redundancy of signal data. Several typical entropy coding methods are Shannon coding, Fano coding and Huffman coding.

Data compression is classified into lossless compression and lossy compression according to whether the compressed information is lost. According to the compression coding algorithm, the codes can be divided into prediction coding, transform coding, statistical coding, pulse code modulation coding and hybrid coding. Compression data of different effects is generated by different compression techniques.

Compression technology is one of the most important technologies in the generation and development of new media. Compression technology improves the storage efficiency and transmission efficiency of new media information.

\section{Transmission technology}

The essence of communication is to realize the effective transmission of information. It not only transmits useful information accurately, but also reduces unnecessary information during the transmission. Communication transmission technology is the basis for the emergence and development of new media technologies. Having a good transmission system can support the widespread dissemination of new media information. According to different standards, there are many categories of communication, such as wired communication, wireless communication, digital communication, analog communication, multimedia communication and so on. Among numerous communication methods, wireless network communication and mobile communication have become important forms of new media technology circulation. The characteristics of wireless networks and mobile networks are easy to use and fast transmission, and promote the development of new media.

\section{New Media TeChNology ApPlicAtion}

New media relies on the Internet. With the rise of mobile Internet technology, the way of media communication has undergone great changes. Users can use mobile phones, PAD and other mobile terminals to disseminate new media information. New media has gradually become mainstream. The public can easily read the information, watch videos and listen to music through mobile phones, tablets and other mobile terminals for voice and other resources. At the same time, users can also instant messaging and publishing information. Users can make online purchases, pay online and receive online payments through their mobile devices. The new media has dramatically changed people's business models. It is also possible to use various services such as fund transfer, payment and other services through mobile banking, and new media gradually change the way people live, socialize and work.

Smart mobile terminals to promote the rapid development of new media technologies, mobile social media, Internet TV and mobile e-commerce are the new media generated by the mobile terminal. 


\section{A. Social media}

Social media is a tool platform for exchanging ideas and opinions, as well as a vehicle for connecting people. The most influential forms of social media in China include Weibo, WeChat, blogs and more. WeChat and Weibo are the most representative new media social media. In addition to their messaging capabilities, they provide more diverse services based on social media networks such as WeChat Moments, WeChat Pay, WeChat Official Accounts. So that various forms of new media information dissemination, thereby enhancing the influence of new media information. These social media have played a role in the traditional Internet and in the mobile Internet.

\section{B. Internet TV}

Network TV, also known as IPTV (Internet Protocol TV), it is based on broadband IP network, with network video resources as the main body. The TV, PC and handheld devices as display terminals, through the set-top box or computer access to broadband networks, to achieve digital television, time-shifted TV, interactive TV and other services. The emergence of Internet TV has brought a new way of watching TV, which has changed the passive mode of TV viewing and realized the convenient way of watching TV. Internet TV is an important way for the dissemination of new media information.

\section{Mobile e-commerce}

E-commerce is a combination of new media technologies and business activities. In the open Internet environment, based on the browser / server application, buyers and sellers conduct various business activities to achieve online shopping, online trading and electronic payment. The most common modes of ecommerce include B2B, B2C, C2C, $\mathrm{O} 2 \mathrm{O}$, depending on the role of both parties to the transaction.

1) Online shopping. People can shop anytime, anywhere, according to their needs.

2) Mobile payment. The representative of mobile electronic payment is mobile banking service, Alipay and WeChat. Users can use the mobile terminal to complete the payment quickly and conveniently, which not only relieves the pressure of carrying cash, but also solves the problems of counterfeit money and accounting.

3) Micro-store, micro-business and P2P. People complete the transaction through the WeChat Moments to promote the product. P2P is a new lending model, it is to gather small loans to the needs of people with financial needs.

4) Investment and financial management. People can arrange their own property more reasonably.

5) Electronic reading. People can more easily read some famous works at home and abroad.

With the continuous development of computer technology, the emergence and dissemination of new media information has shown diversified and mobile characteristics, resulting in more and more applications and accelerating the development of new media technologies.

\section{RESEARCH ON NeW MEDIA DEVELOPMENT}

The emergence and dissemination of new media information has had a tremendous impact on people's way of life. On the whole, the development of new media presents the following trends:

Fragmentation is a feature of the mobile Internet era, and the fragmentation of the media has brought many opportunities to the we media. Individuals can generate and disseminate media information, the we media needs to to emphasize professional and distinctive features to ensure that they are not obscured in massive media information.

Social media is the only form of media future. For example, the People's Daily, the initial form of the newspaper, but in the new media era, it is an omnimedia platform, showing the People's Daily in the mobile Internet era of three-dimensional and comprehensive influence.

From the consumer psychology and behavior to analyze people, discover the true characteristics of people.

Media need to be we media, each media has a unique value. Only with a personalized label, the media can go further.

\section{CONCLUSION}

There is a difference between media information and traditional media information. Everyone can use the new ideas and rules to create a new mode of information 
dissemination. As each individual has the ability to communicate, the traditional media structure begins to disintegrate, and consumers no longer depend entirely on traditional media for information, which also marks the birth of the media age. With the continuous development of science and technology, people have entered a new media era. The new media has not only enriched the ways of generating information, but also brought a great impact on people's life.

\section{REFERENCES}

[1] Wang Zhongsheng. Multimedia Technology and Applications [M]. Beijing: Tsinghua University Press, 2016.1

[2] Wang Zhongsheng, Chen Guoshao. New Media Technology and Application [M]. Beijing: Tsinghua University Press, 2017.9

[3] Zhang Liying, Wang Shixiang. Information Theory and Coding Basic Course [M]. Beijing: Tsinghua University Press, 2010

[4] Li Liang Hui .Flash CS6 entry and advanced [M] .Beijing: Tsinghua University Press, 2013

[5] Peng Xiaoxia, He Xiaoqin. Photoshop CS6 from entry to master [M] Beijing: Tsinghua University Press, 2014

[6] Huang Wei, Wang Yinghua Premiere Pro CS6 Chinese version of the standard tutorial [M] Beijing: Tsinghua University Press, 2014

\section{ACKNOWLEDGMENT}

Fund support: Shaanxi Education Department Special Fund Project number: Shaanxi Education Finance[2013] 23

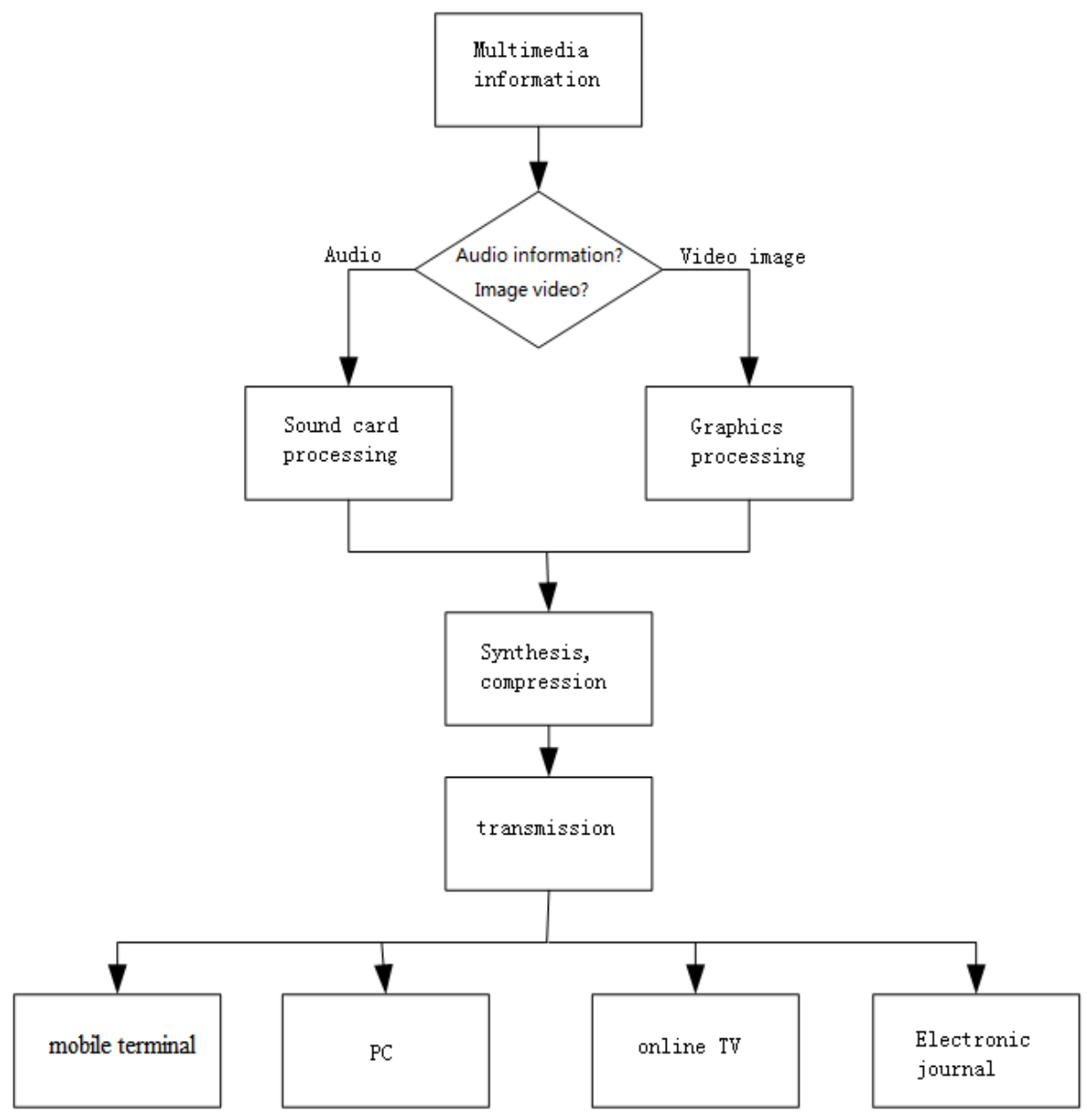

Figure 1. General information on multimedia information processing 